Please do not remove this page

RMIT

UNIVERSITY

\title{
Evidence-based persuasion: A cross-cultural analysis of entrepreneurial pitch in English and Spanish
}

Ducasse, Anamaria

https://researchrepository.rmit.edu.au/esploro/outputs/9921907810401341/filesAndLinks?institution=61RMIT_INST\&index=null

Ducasse, A. (2020). Evidence-based persuasion: A cross-cultural analysis of entrepreneurial pitch in English and Spanish. Journal of International Entrepreneurship, 18, 492-510.

https://doi.org/10.1007/s10843-020-00278-0

Document Version: Accepted Manuscript

Published Version: https://doi.org/10.1007/s10843-020-00278-0

Repository homepage: https://researchrepository.rmit.edu.au

(c) Springer Science+Business Media, LLC, part of Springer Nature 2020

Downloaded On 2023/04/26 19:17:30 +1000 


\title{
Evidence-based persuasion: A cross-cultural analysis of entrepreneurial Pitch in English and Spanish
}

\begin{abstract}
Since the definition of elevator pitch e.g. Pagliarini, (2001), researchers have debated the 'right' way to pitch an idea. Entrepreneurial pitch is widely taught in business communication and although most research is based on the content e.g. Pollack, Rutherford and Nagy (2017), the rhetorical and linguistic characteristics are less researched in English e.g. Daly and Davy (2016 a,b), or indeed other languages. This paper, reports on the rhetorical relations found within obligatory and optional stages in Pitch discourse from a previously analysed data set comprising two different corpora: ten English and ten Spanish sets of entrepreneurial Pitch. The conclusion suggests a tendency to use five rhetorical relations: RESULT, ELABORATION, PREPARATION, BACKGROUND and PURPOSE emerging within the obligatory stages in all 20 Pitches. In addition, an EVALUATION relation is present in the Pitches that are funded and thus are successful. The intercultural analysis of the two spoken corpora suggest that obligatory stages in Pitch - may affect the Rhetorical Structure Theory relations used to convey speakers’ intentions in British English and Peninsular Spanish.
\end{abstract}

\section{Key words}

oral business communication, cross-cultural rhetoric, cross-cultural pragmatics, genre speaking, Rhetorical Structure Theory

\section{Introduction}

Spanish and English cross-cultural studies comparing spoken rhetoric from business are few. Despite studies comparing genre in written discourse in English and Spanish e.g. Martín-Martín (2005) few compare spoken business discourse. Taboada (2016) calls for comparisons across languages and text types to provide insights into language universals and language change. Her discourse studies (2004) are among the few comparing spoken Spanish and English appointment making. García-Gómez, $(2017,2018)$ identifies how business experts exert interpersonal influence in business negotiations in the three-part exchange following TV-Pitch in Spanish and English and explores the similarities in how the experts persuade entrepreneurs to comply to their requests as a condition for investing and becoming partners. This study offers a taxonomy of Rhetorical Structure Theory relations for successful pitch in Spanish and English. Findings in both studies show the similarity of spoken Spanish and English business communication.

\section{Literature revision}

Pitch falls within persuasive communication which has been characterised in fields ranging from communication and social psychology to political science and advertising (Stiff and Mongeau 2003). Most studies focus on Pitch successfully persuading an audience; persuasion meaning "any message that is intended to shape, reinforce, or change the response of another or others" (Miller, 1980, p.11). As a working definition it is delimited to Pitch to investors. It is a context where it is necessary for both the sender and recipient of a message to consider something to be persuasive O’Keefe (2016).

Because it is persuasive, Pitch is the prime mode of interaction with stakeholders (Baron and Markman 2000, 2003). Its definition emerged from universities and business schools across the United States. "The entrepreneurial Pitch is a brief description of the value proposition of an idea or company which entrepreneurs use to present ideas to potential equity shareholders such as business angels and venture capitalists in the hope of securing the requisite equity or strategic partners for their business” Daly \& Davy (2016a, p.121).

There is no doubt that the pitcher is scrutinised to unlock the reasons for success. Few studies have been undertaken from the perspective of the pitcher (e.g. Belinsky \& Gogan, 2016). Most report that the pitcher's personal attributes have the highest influence on outcomes (Clarke 2008) followed by investor interests in profit. A successful pitcher should be prepared, credible and reinforce their legitimacy through the message (Chen, Yao and Kotha 2009; Pollack Rutherford and Nagy 2017). In addition, their delivery should show enthusiasm and commitment (Cardon, Mitteness \& Sudek 2016). Pitchers also need to take care against any flaws. Investors reject 
pitches with perceived flaws in the first stage of the process; those with no fatal flaws however progress with a greater chance of success (Maxwell, Jeffrey and Levesque 2011).

Analysis of public speaking in business (without slides) appears absent from the literature (Baccarani \& Bonfanti 2015) and as a potential key to success for corporate communication it seems counter intuitive to ignore Pitch (e.g. Miller and Stone, 2009; Yale, 2014). Pitch is also a type of public speaking but studies on pitch that claim to survey communicative behaviour in the sub-genre TV-Pitch display a lack of linguistic or pragmatically grounded discussion except for Spalton's (2010) and Daly and Davy’s (2016b) work. For example, Daly \& Davy (2016b) report on an analysis of 13 successful Pitches, from the UK on Dragon's Den and provide a model that supports instructors teaching Pitch by making explicit the rhetoric and linguistics involved in improving a Pitch.

Pitch falls within business communication as a type of English for Specific Purposes (ESP). Genre analysis has been used previously in the ESP Genre framework which originally focused on business communication (Bhatia 2004, Bhatia 2014). Genre analysis can be used to analyse communication in specific genres and it traditionally identifies Moves and then Steps within them, which the Systemic Functional Linguistics or the Sydney School (e.g. Hasan 1989, Martin 1992) identifies as Stages.

Examples of stages in Pitch (Figure 1) show findings from a previous study on Pitch (the author) that identify stages, being either obligatory or optional. The functionality of each stage defines the purpose of the stage in the genre described.

Figure 1 Cross-cultural Pitch stages

\begin{tabular}{|l|l|l|}
\hline Stage & Frequency & Functionality \\
\hline Opening & Obligatory & To identify context by name /origin and company/ product, \\
\hline Proposition & Obligatory & To state the financial motivation \\
\hline Product & Obligatory & To describe the product and explain its development \\
\hline Purpose & Optional & To reinforce the need for the product and/or its results or claims \\
\hline Business & Optional & $\begin{array}{l}\text { To clarify how the product works in the market place by explaining any } \\
\text { business development }\end{array}$ \\
\hline Closing & Optional & $\begin{array}{l}\text { To indicate the end of the monologue and/or to invite interaction with the } \\
\text { audience }\end{array}$ \\
\hline
\end{tabular}

Martin and White (2005) developed a way to present Stages within a genre (e.g. column 1 Figure 1) in linear form as a schematic structure. This linear layout (Figure 2) was applied to findings from a previous study (the author) which proposes evidence for the difference between the obligatory and the optional stages observed in the English /Spanish combined corpus. Below in bold the obligatory stages appear in order of appearance and these are followed by the optional stages in order if more than one and in square brackets.

Figure 2 Proposed obligatory and optional stages for Pitch in Spanish and English

\begin{tabular}{|c|}
\hline Sequence of obligatory and optional for Total corpus $n=20$ \\
\hline Opening $_{\lambda}$ Proposition $_{A}$ Product [Purpose ${ }_{A}$ Business $_{\lambda}$ Closing] \\
\hline Sequence of obligatory and optional for English corpus $n=10$ \\
\hline Opening $_{\wedge}$ Proposition $_{\wedge}$ Product $_{\wedge}$ Closing [Purpose $_{\lambda}$ Business] \\
\hline Sequence of obligatory and optional for Spanish corpus $n=10$ \\
\hline Opening $_{\lambda}$ Proposition $_{\lambda}$ Product $_{\lambda}$ Purpose $\left[_{\lambda}\right.$ Business $]$ \\
\hline
\end{tabular}


An extension on the schematic structures study investigates here whether stages 'reveal different configurations of linguistic patterns' (Eggins and Slade 1997:235), in particular repeated patterns of rhetorical relations between clauses. In this study, the term 'rhetorical relations' is used in reference to the framework of Rhetorical Structure Theory (RST), as described in Mann and Thompson (1988). Studies of text analysis using RST have shown that it is, indeed, useful to capture the underlying structure of texts (Taboada 2006:429), so a brief introduction to the framework is presented in section 4 preceding the analysis.

\section{Aim of the study}

From the literature review, linguistic components that occur within stages in Spanish and English remain to be determined. This leads to an underlying hypothesis that an innovative analysis combining an adaptation of Genre Theory and RST (building on research that contrasts spoken Spanish and English in appointment scheduling (Taboada 2004) would a) illustrate how the languages compare cross-culturally through rhetorical choices and b) build on the linguistic analysis for English from Daley and Davy (2016b).

To achieve this the first aim is to identify, define and exemplify the Rhetorical Structure Theory relations across the corpus and the second aim is to identify any predominant rhetorical features within the discourse stages. What is of interest here is the recurrence of specific relations within stages to identify a pattern or trend because such findings would represent the relations that appear in different stages and form recurrent patterns in the ways clauses within texts are related. The significance is not so much the frequency of the relations within the text; rather, it lies in the qualitative patterns identified, which brings us to the application of rhetorical relations to different languages and to the structure within Pitch as a genre.

\section{Data}

The two corpora for this study were used for a previous analysis in which six stages were identified as set out in section 2. The same corpora were compared by language and gender to identify number and / or order of stages and were used to hypothesize a tendency for a preferred order and propose obligatory stages for Pitch (in bold type) from Spanish and English, in a sample range of 20 speakers. The corpora were derived from 10 participants in Spain on 'Tu Oportunidad', and 10 participants in England on 'Dragons' Den'. The data comprised transcripts ( see appendices 1 and 2) made by the FUNDETT research team from the limited programs, available online and via 'on-demand' as used by Pollack, et al (2017) and Daly \& Davy (2016). The selection ensured equal numbers of men and women and parallel products in two languages. The UK pitches were selected from episodes from 2012 to 2014. The Spanish pitches were from 2013 when it ran for one season.

The context in each country was an episode made up of four persuaders taking turns to pitch to the panel of potential investors who were local in each corpus and heard Pitches on varied proposed new ventures from underwear to dog food . Pitch was delivered following strict rules from the UK website: "Entrepreneurs must start the meeting by stating their name, the name of the business, the amount of money they are pitching for and the percentage of equity they are willing to give away in their company. They must follow this with a Pitch of up to three minutes. If it exceeds three minutes, the Dragons can stop entrepreneurs at any point, but they cannot interrupt the initial Pitch”. This was translated for the Spanish website.

\section{Theoretical Framework and methodology: Rhetorical Structure Theory}

RST was chosen as a framework to identify rhetorical relations within stages because 'when building a sentence, speakers choose among a set of alternatives that relate portions of the text (or sentence)' and these 'rhetorical relations place emphasis on the writer's intentions and the effect of the relation on the audience" (Taboada 2006:570). Because Mann and Thompsons identify, list and exemplify relations, one possibility is to create a taxonomy of relations, and observe in which types of stages they appear.

The main framework proposed for this study follows Mann and Thompson (1988) which specifically looks at organization in texts by analysing the relations between parts of texts. In RST, to determine the textual structure every part of the discourse is connected to another and the way parts are joined is called a relation. Different relations have different names and there were originally 24 classified into subject relations (e.g. Elaboration, Circumstance, Cause, Restatement etc.) and presentational relations (Motivation, Background, Justify etc). See 
figure 3 below Mann and Thompson (1988). In addition to this list, Mann (2005) added Joint, Means, Preparation and Unconditional to the RST website.

The rhetorical relations listed are used to relate elementary discourse units. The central idea is a nucleus $(\mathrm{N})$ and related or secondary ideas are satellites (S). To apply the RST analysis the analyst makes judgements on how to divide the entire text using the Elementary Discourse Unit guidelines and then decide whether a clause is a nucleus or a satellite from the meaning in context before determining finally how the parts relate by selecting from a list of defined relations with examples that have been previously compiled by other researchers e.g. to provide 'BACKGROUND' to another clause or 'JUSTIFY', or provide 'EVIDENCE', show a 'PURPOSE' or function as a 'RESTATEMENT' within a text. The relations are further divided into four fields by the: effect on the nucleus, effect on the satellite, effect on both or the effect of the text on the receiver (Taboada 2006). The fields are represented by directional arrows when text relations are set out as tree diagrams linking all parts of a text (see author).

Figure 3 Mann and Thompson (1988)

Circumstance
Solutionhood
Elaboration
Background
Enablement and Motivation
Enablement
Motivation
Evidence and Justify
Evidence
Justify
Relations of Cause
Volitional Cause
Non-Volitional Cause
Volitional Result
Non-Volitional Result
Purpose

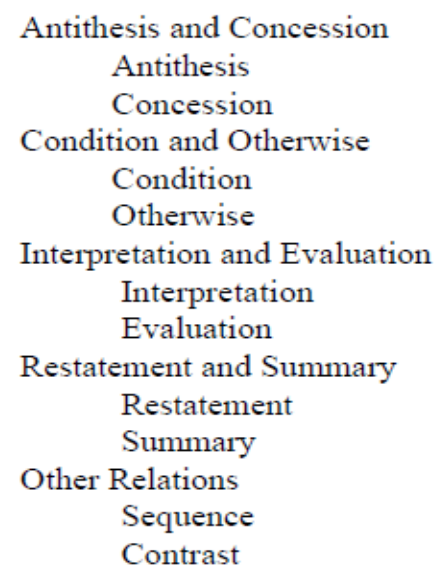

The main difference between Rhetorical Structure Theory and other theories is that rhetorical relations place emphasis on the intentions of the person communicating the message and the effect on the reader. (For a comparison of rhetorical relations to other approaches, see Taboada and Mann, 2006). If Pitch is recognised as a type of persuasion defined as "any message that is intended to shape, reinforce, or change the response of another or others” (Miller, 1980:11) and as O’Keefe (2016) aptly claims, it is necessary for both the sender and recipient of a message to consider something to be persuasive, then RST could be utilized to illuminate communicative intentions, in this case in a spoken discourse.

With regards to spoken discourse Chafe (1996) discusses the complications of using RST trees to represent discourse claiming that 'a tree diagram falls short of capturing the gradual development of ideas through time under the influence of both cognitive and social goals and constraints. People move from one thought to another, chunking certain thoughts together to be sure, but continually influenced by ongoing processes of memory as well as by the thoughts, language, and actions of others' (Chafe, 1996: 55-6). Hence since the corpus is spoken and divided into relatively short stages, RST trees will not be used to represent the internal relations of the stages. In exemplifying the taxonomy, Nucleus and Satellite only will be used to show the field. The relations between the stages themselves as part of the whole text also fall beyond the scope of this analysis. This explanation is simplified but enough to understand the analysis that follows which depends on listing the taxonomy of relations exemplified by naming Satellite and Nucleus relations.

RST analysis, first used for English, has now been applied to corpora of a substantial size (Carlson et al. 2001), but there are few studies in languages other than English among them are German (Stede 2004), Spanish and Basque, see Cunha et al (2011). Work in Spain confirms that RST can be applied to Spanish as well as English written texts (Cunha and Iruskieta 2010). Taboada (2004) presents an analysis of RST and how certain relations correlate within an analysis of a dialogue genre.

In studies where Genre Theory (GT) is applied, RST can later be used to extend a generic analysis for example in other comparative works on persuasion of spoken Spanish and English. The two methodologies were originally used in combination for written text analysis but have been combined for task-oriented spoken discourse analysis e.g. Taboada (2001, 2004) and Taboada and Lavid (2003). In using these methods to analyse appointment scheduling to uncover rhetorical and thematic patterns, Taboada (2001) shows striking similarities, between spoken English and Spanish appointment making dialogues. The findings reveal how some RST relations correlate 
with stages in a dialogue genre, showing preference for an ELABORATION relation between clauses with the next four common relations being CONCESSION, CONDITION, CAUSE and RESULT, all relating to the subject matter. The relations correlating with different stages within the conversation analysed using GT. Regarding combining the two frameworks Taboada (2016) called for a more exhaustive study of different genres to throw light on the relationship between genres and RST relations.

The first step in the RST analysis is the division of the transcription into units to code. During Pitch there are no interruptions to the argument making it ideal to analyse as a genre and to apply RST. One might assume the transcriptions neatly divide into clauses, almost as in a written text, where "the usual division rule is that each independent clause, along with all of its dependencies of any sort, constitutes a unit” (Chafe 1996:430). The pauses were marked into the transcriptions to use as guides for checking the text division (e.g. appendices 2 and 3 in English and Spanish, bearing in mind that in speech, it is intonation that divides units (Taboada and Mann 2006) hence possibly posing "a problem for spoken language, where units are usually considered to be intonation units, and not necessarily independent clauses” (Chafe 1996: 430). The divisions by independent clause were found to neatly map onto the stages and consequently onto the RST divisions. Once each pitch was split into EDUs the second step entailed a detailed analysis of the relations. For this project the entire corpus was coded for relations by one researcher.

The RST was recoded within each stage (listed figure 2) to enable a comparison with original analysis and calculate intra-rater reliability nearly a year later. The selection that was recoded comprised $32 \%$ of the combined corpora (the successful pitches $n=7$ from the total 20) and a $92 \%$ intra-rater agreement was calculated. The analyst applied judgement to deduce the intended meaning of the text, recoded relations following examples from online RST manuals and the differences were recoded. Most of the disagreements were ELABORATION or BACKGROUND that were recoded to a more precise relation or selections within the same coding type e.g. RESULT and CONSEQUENCE where the better option was selected. An example of recoding below was first coded as two elaborations but the second time as an ELABORATION followed by a RESTATEMENT.

Example 1 successful Spanish female 16

Extract 1

utilizamos ingredientes de kilómetro cero

We use local ingredients

es decir que están fabricados a menos de cien kilómetros de distancia

that is to say they are made less than a hundred kilometres away

\section{Analysis and Results}

This section is presented in three steps:

Step 1 was to identify the RST categories across the corpus

Step 2 identifies any predominant rhetorical features within each of the discourse stages of successful pitch Step 3 identifies features within each of the discourse stages with RST.

\subsection{Taxonomy of RST relations}

Step 1 was to identify the RST categories across the corpus of 20 Pitches, so the entire corpus was divided into 381 Elementary Discourse Units. The taxonomy comprised twenty RST categories for Pitch in Spanish and English (presented in table 1), Of these the most common, approximately half, will be defined and exemplified in order of frequency.

After considering the options and the elaborations made by other RST researchers for other contexts the original Mann $(1988,2005)$ lists relations were employed for the analysis. The reason for following these original lists was that the corpus was restricted to short prepared speeches and both Spanish and English work with clauses and dependent clauses. As expected, unassignable categories failed to emerge for discussion.

Pitch was characterized in terms of five main relations between clauses that determine a rhetorical pattern in order of frequency: ELABORATION, RESULT, PREPARATION BACKGROUND and PURPOSE. The greatest similarity lies in the frequency that both languages use the same quantity of PURPOSE relations between clauses. The English use more of the ELABORATION, COMMENT AND TEMPORAL relations which the Spanish utilise less in this corpus. The analysis also shows some differences in the relations with negligible frequency in the data. In a qualitative application of RST, it is more important which relations are used and in which positions, rather than the frequency 
for the sample size. The women drew more on these relations: ELABORATION, RESULT, DEFINITION, REASON and CONTRAST. The men however used more of the TEMPORAL relation. There were also observable differences in the raw count relation categories, with negligible frequency, however.

The results are determined by the nature of Pitch. Table 1 column 1 shows the relations with a frequency closest to $10 \%$ and upwards, with the raw counts in columns under the variables: language and gender. The variables language and gender are commented on, followed by the variable success discussed in part 2 . Of the five relations that stand out, they represent close to $60 \%$ of the relations and are discussed in detail. There is an example listed for each below, but it does not advance the argument to explain and exemplify every single relation beyond these. As was expected no unclassifiable text or new relations were found and the RST manuals have comprehensive examples for all the listed relations in the data set.

Table 1 Raw numbers relations counts

\begin{tabular}{lcccccc} 
& & Total & Spanish & English & unfunded & success \\
\cline { 2 - 7 } & & $\mathrm{n}=20$ & $\mathrm{n}=10$ & $\mathrm{n}=10$ & $\mathrm{n}=13$ & $\mathrm{n}=7$ \\
\hline & $\begin{array}{r}\text { Total } \\
\text { RAW }\end{array}$ & RAW & RAW & RAW & RAW \\
\hline ELABORATION & 20.5 & 78 & 29 & 47 & 55 & 23 \\
\hline RESULT & 11.3 & 43 & 17 & 26 & 36 & 7 \\
\hline PREPARATION & 9.7 & 37 & 21 & 16 & 22 & 15 \\
\hline BACKGROUND & 9.2 & 35 & 16 & 19 & 23 & 12 \\
\hline PURPOSE & 8.4 & 32 & 16 & 16 & 24 & 8 \\
\hline
\end{tabular}

On the one hand, the ELABORATION relation is intrinsic to the meaning of an object being spoken about and/or essential to understanding the context. In Pitch, ensuring the listener understands the product attributes and the business context is crucial.

Extract 2 successful English female 8

Billie \& Margot is the first company in the UK to produce and sell iced treats for dogs (N)

It all began some time ago with Billie our first pet Labrador (S)

The example shows how the satellite (S) gives additional information or detail about the company introduced in the nucleus $(\mathrm{N})$. This relation is extremely common, especially to show relations across large spans of information. The satellite provides additional, more specific, information about the nucleus.

In a RESULT relation, the situation presented in one span is the cause of the situation presented in the nucleus. It is like a consequence relation, but it has not yet been realized.

Extract 3 successful Spanish male

en este caso se queda la maceta pequeña

in this case the pot is too small

y necesitamos trasplantarla a un lugar más grande,

and we need to transplant it to a larger one

In the example we can see that if a plant grows out of its pot the result is that it should be moved to a larger one.

The BACKGROUND relation establishes the context or the grounds with respect to which information is to be interpreted; in this case most of the information presented is about the persuader and/or the company.

Extract 4 successful /Spanish / female / persuader

Me llamo Evelyn Celma.

My name is Evelyn Celma.

Soy la fundadora y gerente de Matarrania cosmética natural.

I am the founder and director of Matarrania natural cosmetics.

The example shows how understanding the satellite helps the reader understand the nucleus, but the satellite is not the cause/reason/motivation of the situation presented in the nucleus. 
The PURPOSE relation emphasises the intention. It can be paraphrased as “nucleus in order to satellite”. According to Taboada 2016 it is signalled by discourse markers $90 \%$ of the time, by four different markers in English: and, so that, that, and to making this is one of the most frequent cases of signalling. , the situation presented in the satellite of a purpose relation is only putative, i.e., it is yet to be achieved.

Extract 5 successful English female persuader $\mathrm{x}$ )

We've spent six months formulating the product

to be far superior to anything else on the market.

In a goal-oriented task, it is unsurprising that the speakers demonstrate a purpose in their monologues. Their purpose and motivation can be seen by the amount requested and the percentage share in the business in return.

\subsection{Discourse Stages of successful Pitch and corresponding RST relations}

After identifying the taxonomy for RST drawn from the corpus step 2 of the analysis involved identifying any predominant rhetorical features within each of the discourse stages of successful pitch. To compare, the sequence of stages for the total corpus appears first with the successful Pitch sequence below in Figure 4.

Figure 4 Proposed obligatory and optional stages for successful Pitch

\begin{tabular}{|c|}
\hline Sequence of obligatory and [ optional] for Total corpus \\
\hline Opening $_{\wedge}$ Proposition $_{A}$ Product [Purpose ${ }_{A}$ Business $_{\wedge}$ Closing] \\
\hline Sequence of obligatory and [ optional] stages for successful Pitch \\
\hline Opening $_{\Lambda}$ Proposition $_{\Lambda}$ Product $_{\Lambda}$ Purpose $_{\Lambda}$ Business [Closing] \\
\hline
\end{tabular}

The sequence was distinguishable from the total corpus linear sequence in Figure 1 by the inclusion of the Purpose and Business stages as Obligatory in a successful Pitch and not optional as per the total corpus.

Reports on the discourse features for successful Pitch are summarized in Figure 5 which shows the RST relations that arise proportionally at each obligatory stage followed by the optional stages. The raw numbers in Table 1 column for 'success' pertain to the RST relations underscored in Figure 5.

Figure 5 Genre stages with predominant RST for successful Pitch

\begin{tabular}{|c|c|c|}
\hline Stages & Purpose of stage & $\begin{array}{l}\text { RST relations (Underscored) } \\
\text { pertaining to success }\end{array}$ \\
\hline $\begin{array}{l}\text { Opening } \\
\text { Obligatory }\end{array}$ & $\begin{array}{l}\text { To identify by name, company, product, } \\
\text { origin }\end{array}$ & $\begin{array}{l}\text { PREPARATION } \\
\text { BACKGROUND } \\
\text { ELABORATION }\end{array}$ \\
\hline $\begin{array}{l}\text { Proposition } \\
\text { Obligatory }\end{array}$ & To state the financial motivation & $\begin{array}{l}\text { PURPOSE } \\
\text { CONDITION }\end{array}$ \\
\hline $\begin{array}{l}\text { Product } \\
\text { Obligatory }\end{array}$ & $\begin{array}{l}\text { To justify financial backing by } \\
\text { explaining the nature of the product and } \\
\text { its development }\end{array}$ & $\begin{array}{l}\text { EVALUATION } \\
\text { RESULT } \\
\text { ELABORATION }\end{array}$ \\
\hline $\begin{array}{l}\text { Purpose } \\
\text { Obligatory }\end{array}$ & $\begin{array}{l}\text { To reinforce the need for the produce } \\
\text { and/or its positive outcomes }\end{array}$ & $\begin{array}{l}\text { PURPOSE } \\
\text { CONTRAST } \\
\text { ELABORATION }\end{array}$ \\
\hline $\begin{array}{l}\text { Business } \\
\text { Obligatory }\end{array}$ & $\begin{array}{l}\text { To clarify how the product works in the } \\
\text { market place by explaining any business } \\
\text { development }\end{array}$ & $\frac{\text { TEMPORAL }}{\text { RESULT }}$ \\
\hline
\end{tabular}




\begin{tabular}{|l|l|l|}
\hline $\begin{array}{l}\text { Closing } \\
\text { Optional }\end{array}$ & $\begin{array}{l}\text { To indicate the end of the monologue } \\
\text { and/or to invite interaction with the } \\
\text { audience }\end{array}$ & COMMENT \\
\hline
\end{tabular}

The obligatory Opening for successful Pitch which serves to identify by name, company, product and origin had the corresponding relation from RST of PREPARATION and BACKGROUND which neatly fits because following a general greeting and a personal introduction the speaker establishes the context or the grounds with respect to which information is to be interpreted; in this case most of the information presented is about the persuader and the product.

The obligatory Proposition for successful Pitch serves to state the financial motivation of the persuader and had the corresponding RST relation of PURPOSE and CONDITION both of which clearly connect with a motive for the Pitch and the business conditions under which they are happy make a contract in this context.

The obligatory Product for successful Pitch had predominantly EVALUATION, RESULTS and ELABORATION though there were many relations with less frequency, so it could be inferred that depending on each product a different set of relations were the linguistic resource required to best convey the intention of the speaker and display to the audience the product qualities in order to persuade.

The obligatory Purpose for successful Pitch serves to reinforce the need for the product and/or its positive outcomes. Again, the need for each product along with the product makes each pitch original to stand out so a range of relations are used with no pattern emerging within this corpus.

The obligatory Business for successful Pitch clarifies how the product works in the market place by explaining any business development had the matching relation from RST of RESULT and TEMPORAL with respect to timelines. These show relations regarding what is factual or achieved and over a period. There were too few instances to make any claims about other relations but if the relations appeared within a larger context they would be more significant.

The optional Closing for successful Pitch used to indicate the end of the monologue and/or to invite interaction with the audience was very short and found in only 3 successful pitches but all were English, and the GT analysis showed that for that language all speakers included a closing with the resulting RST relation COMMENT.

Step 3 identifies features within each of the discourse stages with RST. This is carried out by analysing each function separately with RST to explore how the clauses or parts within the stages relate to each function within the pitch. In addition to the frequency of the top five relations a further four predominated over less frequent relations in the count.

Table 2 RST relations for raw numbers column 3 Figure 5

\begin{tabular}{|l|c|c|c|c|c|c|}
\hline & & Total & SPANISH & ENGLISH & UNSUCCESSFUL & SUCCESSFUL \\
\hline & & N=20 & N=10 & N=10 & N=13 & N=7 \\
\hline RST & $\%$ & RAW & RAW & RAW & RAW & RAW \\
\hline CONTRAST & 5.5 & 21 & 7 & 14 & 14 & 7 \\
\hline COMMENT & 5.0 & 19 & 1 & 18 & 15 & 4 \\
\hline EVALUATION & 5.0 & 19 & 8 & 11 & 12 & 7 \\
\hline CONDITION & 4.7 & 18 & 10 & 8 & 14 & 4 \\
\hline TEMPORAL & 3.4 & 13 & 0 & 13 & 7 & 6 \\
\hline
\end{tabular}

The total results in five RST relations added to the list of initial findings most common across the corpora, before the Genre analysis divided the corpus into the stages to describe successful Pitch. The top five relations across the success corpus were PREPARATION, BACKGROUND, ELABORATION, PURPOSE and RESULT coinciding unsurprisingly with the highest frequency across the entire corpus. A pattern was identifiable, and the relations with a higher frequency that emerged for successful Pitch Obligatory stages were CONDITION and EVALUATION. The relations that emerged for successful Pitch optional stages were TEMPORAL, CONTRAST and COMMENT. 
This qualitative finding by relation within obligatory or optional stages for successful Pitch illustrates speaker intentions within different stages of Pitch thereby expanding on a descriptive frequency counts in the taxonomy to provide richer results. A recurrent pattern of relations, which are specific to RST analysis, have emerged within the stages. This pattern has provided a significant result that illustrates the coherence relations within the successful Pitch texts.

This claim is based on the identification of a combination of semantic relations e.g. ELABORATION and functional relations e.g. BACKGROUND resulting from the application of a combination of the two analyses RST and GT. The largest proportional number of rhetorical relations from the sample was selected to hypothesize and discuss, within the previously established stages for successful pitch in Spanish and English, a sequence of preliminary finding for goal directed discourse persuasion. The sample is small and needs confirming in future research using a larger corpus. It was the success that was the criteria for the established obligatory and optional discourse stages. There were no findings for RST in success by language in this sample size.

With regard to previous findings on successful Pitch stages in English figure 1 section 2 Daly and Davy (2016) the Preparation stage and the relations within it map onto their first three steps; the Proposition maps onto step 3 and the Product stage maps onto step 4, the Business achievements stage maps onto step 5 (obligatory for success); Purpose stage could map onto future customers (obligatory for success) and Closing stage (for English only) maps onto steps 9 and 10. Curiously, step 6 or future plans were unmentioned in English or Spanish successful Pitch in contrast to being obligatory in the Daly and Davy English data set.

No one debates that in international business, professionals and students need communication skills whether as English presenters to persuade in Spanish or vice versa. What was heard in each cultural context was different because it was said differently as shown by the stages and differences in RST relations which make the texts coherent but varied in each language. The Pitch, as has been shown in previous research, depends on the orientation of the speakers towards what they should say and the new evidence that has come to light illustrates how the relevant content is delivered could hold to ransom the success of the Pitch and by implication a positive outcome in the form of an investment in their venture.

The comparison of unsuccessful pitching with a previously established sequence of obligatory and optional stages for successful pitch include the following stages: preparation, proposition, product, purpose, and specification and closing .The result from an analysis of the internal rhetorical relations between parts of a text facilitates understanding of texts by identifying the conceptual structure of the relations that underpin coherence. The study offers the more common rhetorical relations for successful persuasion that may have underlying implications for work settings.

These findings support the acquisition of cross-cultural knowledge in the context of business communication and address shifting workplace realities. Implications for business communication educators span teaching necessary communication skills for business students to persuade successfully and avoiding the pitfalls of successful communication thereby meeting global intercultural real-world standards.

From an interdisciplinary cross-cultural perspective, the importance of what is said arising from business research and the discovery of how rhetoric it is said from applied linguistics each offer useful insights. This could be for a Spanish company marketing and persuading in English around the world to international clients or conversely for an English company dealing with the Spanish speaking world where there are cross-cultural persuasion skills to be learned in order to enhance success.

The columns on Table 1 show the differences in the rhetorical patterns for each language context to be different even with the small data set. The issue for the future is to decipher how best to teach the necessary communication skills for business students to meet real-world standards and hence the work has application to support international business student education for cross-cultural communication whether the Stages or the rhetorical relations within them as evidenced by RST. The now explicit obligatory inclusion of for success i.e. opening, proposition, product and purpose and the type of rhetorical relations per stage i.e. ELABORATION, RESULT, PREPARATION, BACKGROUND, PURPOSE and EVALUATION offer possible tools for training and contributing to cross cultural communication in business, specifically focusing on persuasion.

The limitations of small samples do not allow large claims or generalisations. Nevertheless, a small step was taken exploring how GT combined with RST can be used as descriptive tools to help understanding processes in a text, and how a successful Pitch as goal oriented spoken text is created in Spanish or English. A previous study 
published research on 13 successful Pitch this corpus is dominated by 13 unsuccessful ones. A more thorough investigation of these issues with an expanded corpus would be more generalizable and perhaps in future work, point to models of language use in persuasion research.

\section{Conclusion}

The study begins to fill an identifiable research gap by characterising entrepreneurial Pitch and funded bids across Spanish and English men and women in a reality television context. It reports on the rhetorical relations found within obligatory and optional stages in Pitch discourse from a previously analysed data set comprising two different corpus studies: ten English and ten Spanish sets of entrepreneurial Pitch. To the author's knowledge, this is the first study that takes a multi-dimensional analysis to deconstruct the entrepreneurial pitch. The innovative analysis combined an adaptation of Genre Theory and RST, and builds on research that contrasts spoken Spanish and English in appointment scheduling (Taboada 2007). It revealed aspects not previously addressed in the literature e.g. the variables language and gender in this way directly responding to Bird and Schjoedt's (2009) call for research on entrepreneur communication, by reporting on the qualities of successful Pitch which have been found to determine funding decisions (Chen et al 2009).

The results from the analysis suggest a tendency to use five principal rhetorical relations: RESULT, ELABORATION, PREPARATION, BACKGROUND and PURPOSE emerging within the obligatory stages in all 20 Pitches. Importantly, an EVALUATION relation is present in the Pitches that are funded and thus are successful. The intercultural analysis of the two spoken corpora suggest that obligatory stages in Pitch - may affect the Rhetorical Structure Theory relations used to convey speakers’ intentions in British English and Peninsular Spanish.

In this way findings support the acquisition of cross-cultural knowledge in the context of business communication by offering a matrix of characteristics for successful and unsuccessful persuasion that have underlying implications for shifting workplace realities and settings. Implications for business communication educators encompass both the teaching of necessary communication skills in order for business students to successfully persuade; and the avoidance of the pitfalls of unsuccessful communication; the combination of which thereby underpins achieving global intercultural real-world standards.

\section{Footnotes}

1.Taboada and Mann 2006 discuss RST analysts and the analysis process in terms of working in teams and practice to improve skills. The author acquired RST skills with another co-researcher (xx) and together they analysed two other English transcribed spoken corpora comprising 30 local and 30 international students assessed oral presentations and TOEFL iBT speaking tests. They worked on coding RST and calculated an EDU split agreement of $\mathrm{xx} \%$ and a coding of relations at $\mathrm{xx} \%$.

\section{Acknowledgements}

The study was supported by grant (ID No: FFI2013-47792-C2-2-P) Ministerio de Economía y Competitividad. as part of a larger research project EMO-FUNDETT: PROPER

Thanks to the anonymous reviewers who provided insightful feedback.

\section{References}

Baccarani, C., Bonfanti, A., 2015. Effective public speaking: a conceptual framework in the corporate-communication field. Corporate Communications: An Int. J 20, 3, 375-390. https://doi.org/10.1108/CCIJ-04-2014-0025

Baron, R.A., Markman, G.D., 2000. Beyond Social Capital: How Social Skills Can Enhance Entrepreneurs' Success. Academy of Management Executive 14, 106-116. https://doi.org/10.5465/ame.2000.2909843

Baron, R.A., Markman, G.D., 2003. Beyond Social Capital: The Role of Entrepreneurs Social Competence in their Financial Success.” J. of Business Venturing 18, 41-60. https://doi.org/10.1016/S0883-9026(00)00069-0 
Belinsky, S.J., Gogan, B., 2016. Throwing a change-up, pitching a strike: an autoethnography of frame acquisition, application, and fit in a pitch development and delivery experience, IEEE Transactions on Professional Communication, 323-341. DOI: 10.1109/TPC.2016.2607804

Bhatia, V. (2004). Worlds of written discourse: A genre-based view. A \&C Black. Bhatia, V. (2014). Analysing genre: Language use in professional settings. Routledge.

Bird, B., Schjoedt, L., 2009. Entrepreneurial behaviour: Its nature, scope, recent research, and agenda for future research. In: Carsrud A. L., Brännback, M. ( Eds), Understanding the entrepreneurial mind. Springer, New York, 327-358.

Cardon, M.S., Mitteness, C. , Sudek, R., 2016. Motivational cues and angel investment: interactions among enthusiasm, preparedness and commitment, Entrepreneurship: Theory and Practice. DOI: 10.1111/etap.12255

Chafe, W. (1996) 'Beyond Beads on a String and Branches on a Tree', in A.E. Goldberg (ed.) Conceptual Structure, Discourse and Language, pp. 49-65. Stanford, CA: CSLI.

Chen, X.P., Yao, X., Kotha, S., 2009. Entrepreneur Passion and Preparedness in Business Plan Presentations: A Persuasion Analysis of Venture Capitalists' Funding Decisions. Acad. of Management J. 521,199-214. https://doi.org/10.5465/amj.2009.36462018

Clark, C. (2008) The impact of entrepreneurs' oral “pitch” presentation skills on business angels' initial screening investment decisions, Venture Capital. 257-279. DOI .org/10.1080/13691060802151945

da Cunha, I.and M. Iruskieta. 2010. "Comparing Rhetorical Structures of Different Languages: The Influence of Translation Strategies.” Discourse Studies 125: 563-598.

da Cunha, I.J. M. Torres-Moreno, and Sierra, Gerardo. 2011 "On the development of the RST Spanish Treebank .” Proceedings of the 5th Linguistic Annotation Workshop. LAW V '11, 1-10 Association for Computational Linguistics. Stroudsburg, PA, USA

Daly, P., Davy, D., 2016a. Structural, linguistic and rhetorical features of the entrepreneurial pitch Lessons from Dragon’s Den. J. Manage. Dev. 35,1, 120-132. https://doi.org/10.1108/JMD-05-2014-0049

Daly, P., Davy, D., 2016b. Crafting the investor pitch using insights from rhetoric and linguistics. In: Alessi, G.M., Jacobs, G. (Eds.), The Ins and Outs of Business and Professional Discourse Research. Reflections on Interacting with the Workplace. Palgrave Macmillan, London. pp. 182-203. • DOI https://doi.org/10.1057/9781137507686_10

Dragons’ Den Series (2012-14), “Television programme”, BBC2,London,

Eggins S.and D. Slade 1997. Analysing Casual Conversation. London: Cassell.

García-Gómez, A., 2017. Televised entrepreneurial discourse: Conversational structure and compliance gaining strategies, Studies in Media and Communication. 5,1, 104 -116. DOI: https://doi.org/10.11114/smc.v5i1.2426

García-Gómez, A., 2018. Dragons’ Den: Enacting Persuasion in RealityTelevision. Discourse, Context and Media. 21,C, 1-9. https://doi.org/10.1016/j.dcm.2017.09.014

Hasan, R. (1989). The structure of text. In M. Halliday \& R. Hasan, Language, context, and Luntext: Aspects of language in a social-semiotic perspective (pp. 52-69). Oxford: Oxford University Press.

Mann, W. C., and Thompson, S., A. 1988. "Rhetorical structure theory: Toward a functional theory of text organization." Text-Interdisciplinary Journal for the Study of Discourse 8 (3): 243-281.

Martin, J., White, P., 2005. The Language of Evaluation: Appraisal in English. Palgrave Macmillan ,Hampshire, New York.

Martin, J. R. , 1992. English text system and structure. John Benjamins, Amsterdam.

Martín-Martín, P., 2005. The rhetoric of the abstract in English and Spanish scientific discourse: A cross-cultural genre-analytic approach. 21, Peter Lang.

Maxwell, A. L., Jeffrey, S. A., \& Lévesque, M. (2011). Business angel early stage decision making. Journal of Business Venturing, 26(2), 212-225.

https://doi.org/10.1016/j.jbusvent.2009.09.002 
Miller, T.C. ,Stone, D.N. , 2009. Public speaking apprehension (PSA), motivation, and affect among accounting majors: a proof-of-concept intervention, Issues in Accounting Education, 24 ,. 3, 265-298. https://doi.org/10.2308/iace.2009.24.3.265

Miller, G. R., 1980. On being persuaded: some basic distinctions. In: Roloff, M.E, Miller G. R., ( Eds.), Persuasion: new directions in theory and research. 6, Sage, Beverly Hills, CA pp. 11-28.

O’Keefe, D. J. Persuasion: Theory and research 3rd Ed.. Los Angeles, CA: Sage Publications.

Pagliarini, R. 2001. What is an elevator pitch? American Venture Magazine, 31, 31-32.

Pollack, J. M., Rutherford, M. W. , Nagy. B. G. 2017. Preparedness and cognitive legitimacy as antecedents of new venture funding in televised business Pitches. Entrepreneurship Theory and Practice. 36, 915-939. https://doi.org/10.1111/j.1540-6520.2012.00531.x

Spalton, P., 2010. Dragon's Den: The Perfect Pitch: How to Win Over an Audience. Harper Collins , London.

Stede, M. 2004. The Potsdam Commentary Corpus. In2004 ACL Workshopon Discourse Annotation, pages 96-102, Barcelona, Spain.

Stiff, J.B., Mongeau, P. A., 2003. Persuasive communication 2nd ed. Guilford, New York; London.

Taboada, M., 2016. http://www.sfu.ca/rst/ Simon Ford University RST website developed by William Mann maintained by Maite Taboada.

Taboada, M., 2004. Building Coherence and Cohesion: Task-oriented Dialogue in English and Spanish. John Benjamins, Amsterdam/Philadelphia

Taboada, Maite, and William C. Mann. 2006. "Rhetorical structure theory: Looking back and moving ahead." Discourse studies 8 ( 3):423-459.

Taboada, M and Mann, W. 2005 -2016. http://www.sfu.ca/rst/ Simon Ford University RST website developed by William Mann maintained by Maite Taboada. accessed 07/09/2017

Taboada, M.2001. "Collaborating through talk: the interactive construction of task-oriented dialogue in English and Spanish." Unpublished Ph. D. dissertation, Universidad Complutense, Madrid.

Taboada, M. 2006 "Discourse markers as signals (or not) of rhetorical relations." Journal of Pragmatics 38 (4): 567-592.

Taboada and Mann 2006 Rhetorical Structure Theory: looking back and moving ahead Discourse Studies Vol 8(3): 423-459

Taboada, M., Lavid, J., 2003. Rhetorical and thematic patterns in scheduling dialogues A generic characterization Functions of Language. 10,2, 147-178. DOI: 10.1075/fol.10.2.02tab

Tu Oportunidad 2013 programa de RTE televisión española

Yale, R. N., 2014. The impromptu gauntlet: an experiential strategy for developing lasting communication skills . Business and Professional Communication Quarterly. 77, 3, 2. 81-296. https://doi.org/10.1177/2329490614537874

\section{Appendices}

Appendix 1 Divisions of stages with pauses in Spanish ( (hh) and/ or // )

\begin{tabular}{|l|l|}
\hline Sample Transcript Spanish Pitch & Genre stages \\
\hline $\begin{array}{l}\text { Me llamo: / Evelyn Celma } \\
\text { soy la fundadora y gerente de Matarrania cosmética natural // (hh) }\end{array}$ & preparation \\
\hline $\begin{array}{l}\text { y vengo a pediros veintinueve mil euros } \\
\text { a cambio de un ocho por ciento de mi empresa (lapso = 4) //// }\end{array}$ & proposition \\
\hline
\end{tabular}


El laboratorio de cosmética: natural Matarrania está ubicado en el territorio del Matarrania // en: a provincia de Teruel de ahí su nombre /

es una cosmética / jeficaz! //

sobre todo porque contiene aceite de oliva virgen extral

además de tener unas excelentes propiedades: regenerantes y protectoras de la piel //

En la medida de lo posible utilizamos / materia prima local /

y utilizamos ingredientes de kilómetro cero

es decir que están fabricados a menos de cien kilómetros de distancia

(hh)

porque pensamos que eso es importante

para apoyar: a la economía rural: arraigada a la tierra //

No es una cosmética para grandes masas //

porque tiene unas texturas densas / suntuosas

es un producto concentrado con delicados aromas silvestres / (hh)

y pienso que va a gustar mucho a las personas que buscan un producto realmente natural / auténtico / y fabricado en España //

Appendix 2 Divisions of stages with pauses in English((hh) and/ or // )

\begin{tabular}{|c|c|}
\hline Sample transcript English Pitch & Genre stage \\
\hline Hello / my name is Andrew Hannon // & preparation \\
\hline $\begin{array}{l}\text { I’m here today asking for } £ 50,000 \text { /in return for a } 20 \% \text { equity of my } \\
\text { company Thirteen Horror Ltd /// }\end{array}$ & proposition \\
\hline $\begin{array}{l}\text { my business / \{ as I've / tried to show\} / is fear / } \\
\text { I make fear available for people / in the form of two interactive online } \\
\text { experiences / } \\
\text { experiences which started off as short stories / in two self-published } \\
\text { books // } \\
\text { the first of these experiences is called The Magic // } \\
\text { it takes approximately five to ten minutes to complete } \\
\text { and it is terrifying// } \\
\text { the second experience is called The Dare // } \\
\text { it’s done as part of a group } \\
\text { because it's too scary to try by yourself / } \\
\text { it takes about one hour to complete / } \\
\text { it'll scare your socks off /// }\end{array}$ & product \\
\hline $\begin{array}{l}\text { both experiences have been extremely well received // } \\
\text { they have topped the iTunes horror chart in England / America/ Canada / } \\
\text { and Australia } \\
\text { and even made it into the top } 100 \text { charts for fiction in America and the } \\
\text { UK // }\end{array}$ & business \\
\hline $\begin{array}{l}\text { I'm happy to take questions / and apologies for the unorthodox beginning } \\
\text { but I thought I'd try something a bit different to hopefully get your } \\
\text { attention }\end{array}$ & closing \\
\hline
\end{tabular}

